\title{
Life-cycle assessment and deterioration models for masonry arch bridges
}

\author{
A. Tomor \\ Construction and Property Research Centre, \\ University of the West of England (UWE), UK
}

\begin{abstract}
Bridges are key elements of the rail and road network and their safe maintenance is of strategic importance. A large proportion of bridge networks are approaching 100 years and maintenance/strengthening are becoming increasingly important issues. Life-cycle management aims to optimise long-term budgets, interventions, traffic, costs, environmental impact, amongst others. While bridges are only designed for up to 120 years, they often require significant interventions within 50 years. Masonry arch bridges have proved to be highly sustainable long-lasting structures with low maintenance needs. While bridge management currently has an approximately 100-year prospective, informed long-term deterioration models and tools are required before a longer-term view can be adapted. Long-term methodology for assessing masonry arch bridges is discussed and deterioration models proposed for fatigue compressive and shear loading based on laboratory tests. Initial results are considered in terms of practical application.

Keywords: masonry arch bridges, life-cycle analysis, bridge management, bridge fatigue, SN curves.
\end{abstract}

\section{Introduction}

Bridges are key elements of the rail and road network and their safe maintenance is of strategic importance. Sudden bridge failure or collapse does not only endanger human lives, but also have great economic and environmental consequences, e.g. associated repair costs, road closures, diversion. There are over 220,000 railway bridges in Europe, out of which over 35\% are more than 100 years old with a further $31 \%$ aged between 50 and 100 years. Out of all 
European railway bridges $60 \%$ are masonry, 23\% concrete, 22\% metallic [1] (see Figure 1). Similar numbers probably apply for highway bridges. In the United States up to $30 \%$ of bridges have been indicated to be structurally deficient or functionally obsolete [2].

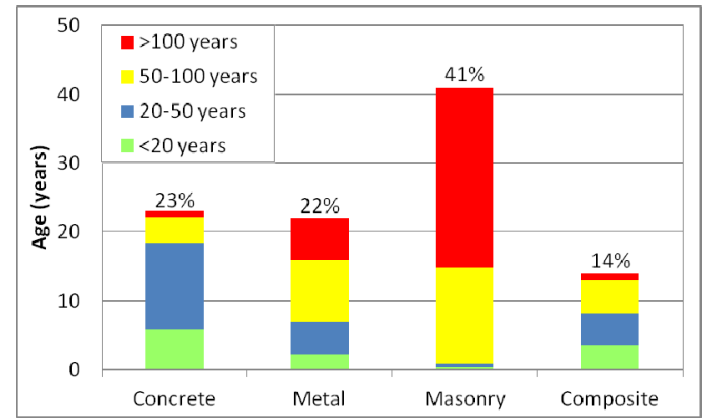

Figure 1: $\quad$ Railway bridge types and age profile.

Apart from the ageing bridge stock, likely to require increasing maintenance and repair, the weight and speed of traffic has also increased significantly during the past century. For example, the weight of railway locomotives has increased from 10 tons (1825) to over 120 tons (2010) in the UK with speeds from $8 \mathrm{~km} / \mathrm{h}$ (1825) to $300 \mathrm{~km} / \mathrm{h}$ (2010) [3]. The fact that most of the old masonry bridges are still carrying traffic without any change to their original form is a testimony to their builders.

While ensuring the safety structural of bridges, life-cycle management aims to optimise long-term traffic demands, maintenance and whole life cost. Without regular maintenance, increased deterioration is likely to occur, leading to premature failure and replacement. Bridges that have lasted over 100 years have been shown to be [4]:

- $\quad$ feasible to maintain (and well maintained)

- $\quad$ adaptable to changes in traffic demands

- $\quad$ originally overdesigned.

While many of the old masonry bridges have already lasted for 200-300 years, with several examples of Roman bridges over 2000 years, new bridges are currently designed for up to 120 years. The choice of bridge design is generally dictated by strength and construction costs, however the cost of maintenance, repair and eventual disposal can make an initially lower-cost solution uneconomical in terms of whole-life costs. Maintenance needs and costs vary for different bridge types. Concrete and steel bridges generally have relatively high maintenance needs and lower life expectancy ( $<120$ years), while masonry bridges have relatively low maintenance needs and higher service lives. It is interesting, that while masonry arch bridges have proved to be the most efficient long-term solutions for bridge design, they are currently completely disregarded as viable options for new built. With the increasing popularity of concrete masonry construction has been gradually disregarded over the past 50-100 years 
to a point that required skills and knowledge have been now been forgotten. It is widely believed that such bridges would be too expensive to build, however with the use of modern technology their actual building costs may be far below expectations. An extended whole-life feasibility study is required for the actual long-term costs to be viably compared.

Sustainability and environmental impact are slowly gaining attention for bridge design. However, if most newly build bridges need replacing within the next 100 years, the long-term environmental impact will be 2-3 times bridges lasting 200-300 years. It is only through long-term perspective (300+ years) that the cost of bridge management and environmental impact can be meaningfully reduced.

In order to enable informed life-cycle management for bridges, tools for assessing their short and long-term structural performance, condition assessment, maintenance/strengthening needs, time schedules, long-term costs and remaining service life are required. The paper will give a brief overview of the currently available guidelines for bridge management in the UK and discuss the tools specifically available for masonry arch bridges. Finally, proposed deterioration models will be presented for masonry with indications for practical application.

\section{Life-cycle assessment for bridges}

As the first step towards managing the bridge stock, accurate assessment of the condition of bridges is essential. In terms of guidance notes, UK Highways Agency has published an Inspection Manual for Highway Structures [5] that outlines the fundamentals of the inspection process (scheduling, planning, performing, recording maintenance/planning process) and helps determine the extent and severity of the bridge condition. The Highways Agency Guidance Document for Performance Measurement of Highway Structures [6] helps determine the extent and severity of bridge condition. The CIRIA publication Masonry arch bridges: Condition appraisal and remedial treatment [7] provides guidance on the management, condition appraisal, maintenance and repair specifically for masonry arch bridges.

The main causes for deterioration during the lifetime of the bridge are traffic and environmental effects, until the condition becomes critical and requires repair/strengthening or replacement. The time interval between construction and the bridge reaches the end of its life is called service life (Figure 2). Interventions, such as maintenance, repair, strengthening can improve the bridge's condition and extend its service life. While there is reasonable scientific background and practical experience to predict the deterioration rate for certain effects, e.g. sulphate attack for concrete bridges, others are far less understood and should be considered with caution, e.g. the effect of long-term fatigue loading on masonry.

The Code of practice Assessment of Highways Structures [8] helps promote good practice for asset management to minimise whole-life costs, optimise the use of resources and provide a sustainable programme of work. 


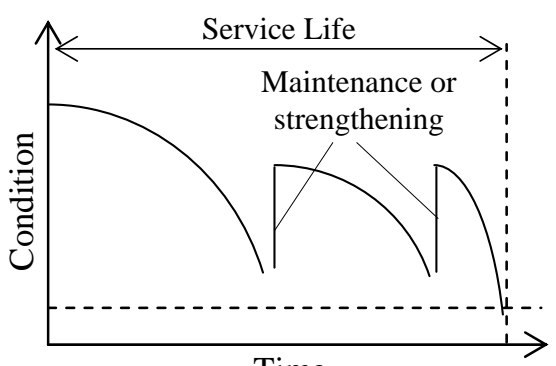

Time

Figure 2: $\quad$ Deterioration model: bridge condition against time.

The UK Department for Transport has recently developed a Structures Asset Management Planning Toolkit [9] to help identify likely deterioration rates over time, schedule maintenance, replacement activities and associated costs based on severity of environmental and traffic exposure. While the toolkit makes a good attempt quantifying the structural condition and maintenance regime for the various bridge types and elements, it may be somewhat conservative with respect to deterioration rates. For example, the maximum life expectancy for mild environmental exposure for masonry, concrete and cast iron is defined as 300 , 100 and 50 years respectively, while it is dramatically reduced to 100, 80 and 80 years due to medium exposure (Figure 3). It is only with informed deterioration models that long-term bridge management can be improved and maintenance needs/budgets can be optimised.

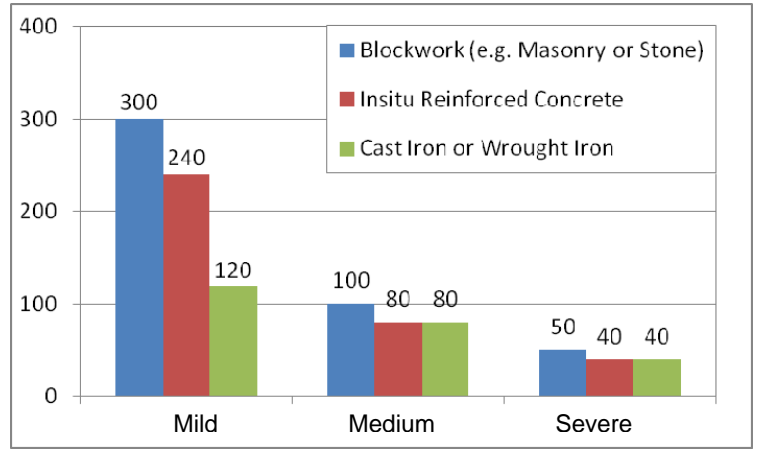

Figure 3: Bridge management framework.

Life-cycle of a bridge includes the initial design and construction, maintenance/repair during its service life and eventual replacement. All associated activities have significant financial, social and environmental implications (e.g. structural choice, materials, method of construction, transport, road closures, maintenance, strengthening etc.). While most decisions are based on costs, social and environmental implication are taken less into account. There is currently very limited guidance available to environmental and sustainability 
aspects during bridge management. Broad guidelines of environmental management are mentioned in BS EN ISO 14040 [10] for which the methodology has been demonstrated by Steele et al. [11] through a study for masonry arch highways bridges. Steele et al. concluded that bridge construction represents the single biggest contributor to environmental impact over the life time of a bridge. While regular maintenance activities have been found to have minimal environmental impact, large-scale strengthening works with associated bridge closure and traffic diversion was shown to cause greater impact than the initial construction. It is therefore necessary to develop viable models for identifying the whole-life environmental impact for bridges to help bridge managers make informed choices.

\section{Life-cycle assessment for bridges for masonry arch bridges}

As mentioned previously, realistic models are essential to allow informed bridge management and optimise long-term budgets. While the rate of deterioration is reasonably well understood for concrete and steel bridges, there is much less knowledge and information available for masonry arch bridges. While deterioration may be caused by loads and environment, the current paper attempts to explore deterioration models for masonry arch bridges specifically due to loading.

There is a range of techniques specifically designed or adapted for masonry arch bridge assessment (e.g. MEXE [12], Harvey [13]; Gilbert and Melbourne [14]; Fanning and Boothby [15]; Brencich and De Francesco [16]; De Felice [17], Melbourne et al. [18], however all of them are based on static test data and the effects of long-term deterioration due to traffic loading or environmental impact is not taken into account into. The first attempt to incorporate long-term service life and define safe long-term loading limits into the assessment is the proposed SMART assessment method (Sustainable Masonry Arch Resistance Technique) [19], although large volumes of fatigue test data on the deterioration models are needed before it can be applied in the field. Fatigue test data is widely available for concrete, metals and polymers, however very little information exists for masonry. A limited number of laboratory test series have been carried out on the cyclic behaviour of brick masonry (AlShebany and Sinha [20]; De Felice and De Santis [21]; Roberts et al. [22]) and on the structural level (Clark [23]; Choo and Hogg [24]; Melbourne et al. [25]), but information on the highcycle fatigue response of masonry is rather limited.

While deterioration due to long-term loading (fatigue) for masonry is not currently a serious concern, with increasing traffic demands bridges are likely to suffer increasing problems and require increasing repair and maintenance activities. In order to avoid unintentional damage and premature failure, the long-term fatigue deterioration phenomenon needs to be understood and safe long-term loading (stress) limits identified. Current guidelines for masonry arch bridge assessment [26] suggest 50\% of the Ultimate Limit State (ULS) as the critical stress limit to avoid long-term fatigue damage, however tests on multiring masonry arches have indicated the fatigue limit to be well below $40 \%$ of 
ULS [25]. Information on deterioration rates is therefore needed to identify if current traffic loading is causing permanent deterioration and reduces the bridge's life expectancy. If so, by how much?

\subsection{SMART assessment}

The proposed Sustainable Masonry Arch Resistance Technique (SMART) (Figure 4) brings together all the existing assessments methods into a single methodology, by considering not only the ultimate load capacity but also the long-term behaviour and residual life for masonry arch bridges. For any likely failure mode the bridge may experience, the associated long-term life expectancy is to be determined with the help of stress vs. number of cycles relationships (S-N curves) and the failure mode with the lowest life expectancy would in turn determine the structure's overall life expectancy and likely strengthening needs.

The first step in the SMART assessment is to determine the form of construction and geometry of the bridge, e.g. arch barrel, material, backfill, spandrel walls, wing walls, presence of internal spandrel walls, foundations.

The second step is to consider the construction materials (e.g. bricks, stone, mortar, extent/arrangement of joints, backfill, surfacing materials, foundations) and their basic properties (e.g. elastic modulus, compressive and tensile strengths, bond strengths and shear strength, thermal coefficient, viscous deformation and fatigue properties). Although some of these are well understood in the case of modern brickwork, there is much less information available for historic brick and stone masonry.

The third step is to identify the loading, including dead loads, live loads and making best estimates for load distribution and soil pressures.

The forth step is to identify the ultimate load carrying capacity (ULS) of the bridge by taking all possible failure modes into account the structure may experience. There are a range of tools specifically available for masonry arch bridges (e.g. MEXE, mechanism method, Finite Elements) but they should be used with caution to ensure that their remits and limitations are properly understood. What is new in the SMART approach is the subsequent assessment of the long-term life expectancy for the various failure modes. Definition of a Permissible Limit State (PLS) has been proposed to help ensure that long-term fatigue deterioration does not reduce the lifetime of the bridge. The assessment of PLS requires the rate of deterioration to be understood for each possible failure mode the bridge may experience and defined as stress level against maximum number of cycles (e.g. years) leading to structural failure (SN curves). SN curves are similar to deterioration in bridge condition mentioned previously (Figure 2) but is based upon stress levels rather than condition. While deterioration models may be reasonably well understood for steel and concrete, there is very little understanding for them for masonry. Loading induced deterioration for masonry can occur due to compression, tension and shear and manifest itself on the structure as ring separation, local crushing, sliding, etc. for which individual SN curves are required to allow long-term fatigue assessment of masonry arch bridges. 
Each failure mode will induce deterioration and failure in the element at different rates. Once ULS and PLS are defined for each possible failure mode, the next step is to identify the lowest of these ('weakest link') for the entire structure, that will determine the ULS and PLS for the overall bridge.

Finally, the life expectancy of the bridge is defined based on the likely stress levels. This may be of particular interest when the loading regime on the bridge is increasing and is likely to reduce the residual life of the bridge. From that the required maintenance, repair and strengthening schemes may be identified to assist informed life-cycle management.

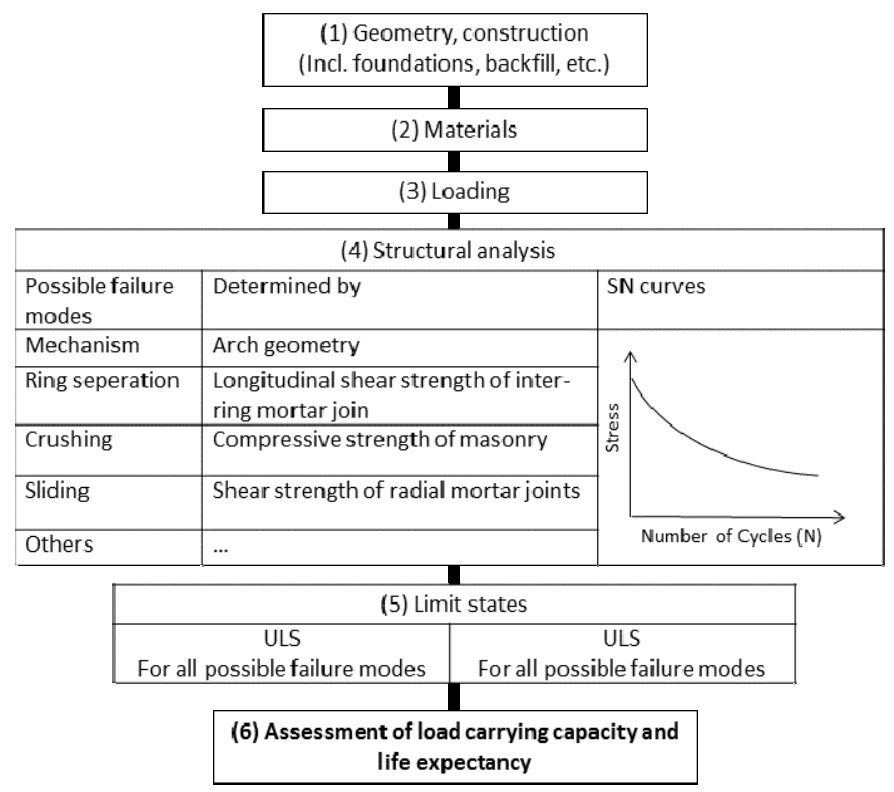

Figure 4: $\quad$ SMART methodology.

\subsection{Deterioration model (SN results)}

As mentioned before, there is very little information available on the rate of deterioration for masonry. Guidelines for masonry arch bridge assessment [26] suggest a fatigue limit of $50 \%$ of the Ultimate Limit State (ULS), but long-term fatigue tests on multi-ring masonry arch barrels indicated that the fatigue limit may be below $40 \%$ of ULS [25] and the permissible limit state (PLS) may be a more suitable option for identifying residual life for masonry bridges.

A small-scale laboratory test series has been undertaken at the University of the West of England, Bristol, UK to study the load-induced deterioration for brick masonry. The test series were intending to provide a set of preliminary test data for compression and shear and propose SN curves.

Small-scale brickwork specimens were built using relatively soft Wienerberger Warnham Red bricks and 1:1:6 cement lime mortar. Specimens 
were tested under compression and under shear (Figure 5) to represent two different failure modes for masonry bridges, material crushing and shear.

First, a series of samples were tested under static loading under compression and shear and the average static strength $\left(\mathrm{S}_{\mathrm{Av}}\right)$ was identified for both failure modes. Subsequently, a series of samples were tested under long-term cyclic compression and shear (minimum of 3 million load cycles, unless failure occurred previously). The cyclic loading was applied between a minimum and maximum stress level $\left(S_{\text {Min }}\right.$ and $\left.S_{\text {Max }}\right)$ that were expressed as percentage of the average static strength $\left(\mathrm{S}_{\mathrm{Av}}\right)$. The minimum stress $\left(\mathrm{S}_{\mathrm{Min}}\right)$ represents the dead load of the bridge due to its self-weight and permanent loads, and the maximum stress $\left(\mathrm{S}_{\mathrm{Max}}\right)$ represents the loads induced by traffic over the bridge. For the test series the minimum stress was kept constant at $10 \% \mathrm{~S}_{\mathrm{Av}}$, and the maximum stress varied between $60 \%$ and $80 \% \mathrm{~S}_{\mathrm{Av}}$ for compression and $50 \%$ and $70 \% \mathrm{~S}_{\mathrm{Av}}$.
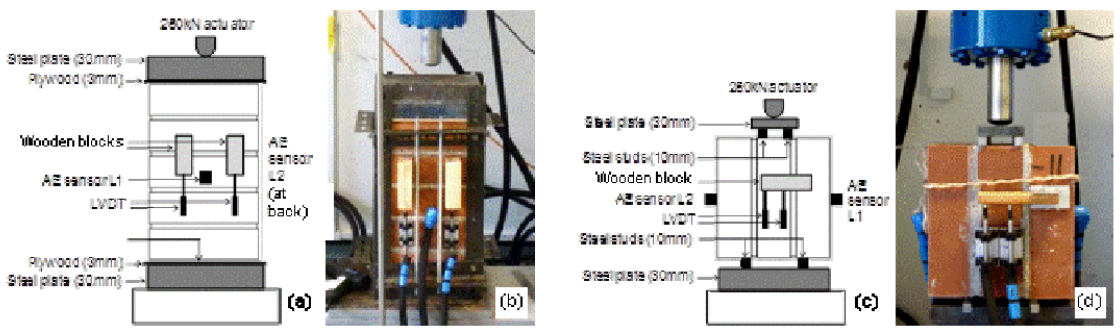

Figure 5: $\quad$ Brickwork specimens tested under compression (a), (b) and shear (c), (d).

Test results are shown in Figure 6(a) and (b) for stress level against the maximum number of cycles at which the specimens failed (log scale). Static test results are indicated as failure at 1 cycle and specimens that did not fail are also included in the graph. Naturally, the lower the stress level the longer the time to failure. There is a relatively large variability within the test results that is not unusual for masonry [27]. While it is not possible to give a single deterministic relationship between stress level and life expectancy, probabilistic analysis may be more suitable to incorporate stress ranges as well as confidence levels.
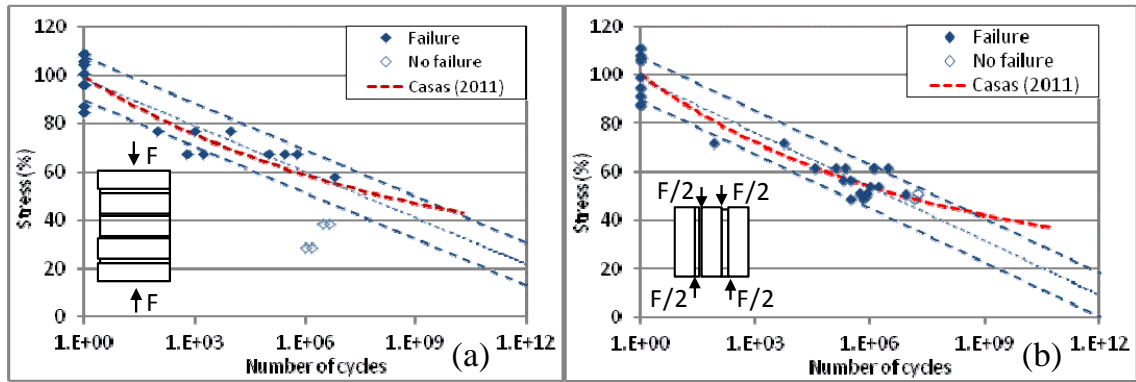

Figure 6: $\quad$ Fatigue test results for compression (a) and shear (b). 
In terms of mathematical relationship, SN type deterioration models have been proposed for masonry by Roberts et al. [22] based on a series of small-scale laboratory tests. Based [28] on Roberts' test results, a probabilistic model was developed by Casas specifically for masonry arch bridges (as shown in Equation (1) and included in Figure 6).

$$
S=A \cdot N^{-B(1-R)} \quad>0.5
$$

where $S$ is the ratio of the maximum stress to the average strength ( $S=S_{\text {Max }}$ / $\mathrm{S}_{\mathrm{Av}}$ ), $\mathrm{N}$ the number of cycles and $\mathrm{R}$ the ratio of the minimum stress to the maximum stress $\left(\mathrm{R}=\mathrm{S}_{\mathrm{Min}} / \mathrm{S}_{\mathrm{Max}}\right)$. An endurance limit of $50 \%$ was assumed. Based on Casas' model and fatigue-creep data, a modified probabilistic model was developed by Tomor and Verstrynge [29].

All the mathematical models however rely on a limited range of test data. While it is quick and easy to produce test results for high stress levels with low number of cycles, it is increasingly difficult to produce test data for stress levels below $50 \%$. Due to practicalities, $10^{8}$ cycles would be around the limit that could be tested under laboratory conditions and would require around 9 month constant use of a loading rig (at $4 \mathrm{~Hz}$ ). $10^{8}$ cycles would however still be insufficient to prove, disprove or identify the existence of a long-term fatigue limit for masonry. Similarly, no fatigue limit has so far been identified for concrete to date [30]. Probabilistic models are therefore the only viable models for estimating the life expectancy for masonry and require large number of test data before accurate SN models can be developed.

In order to demonstrate the practical application of SN curves, examples for stress levels and associated life expectancy are shown in Table 1, based on Casas' model. Under compression, the life expectancy for $50 \%$ average stress level is around $2 \times 10^{8}$ cycles. If the stress level is reduced $5 \%$ (from $50 \%$ to $45 \%$ ), the life expectancy increases 35 times (from $2 \times 10^{8}$ to $8 \times 10^{9}$ ). If the stress level is increased $5 \%$ (from $50 \%$ to $55 \%$ ), the life expectancy reduces to around $1 / 20$ (from $2 \times 10^{8}$ to $1 \times 10^{7}$ ).

Similarly under shear, if the stress level is reduced from $50 \%$ to $45 \%$, the life expectancy increases 18 times (from $7 \times 10^{6}$ to $1 \times 10^{8}$ ) and if the stress level is increased from $50 \%$ to $55 \%$, the life expectancy reduces to around $1 / 12$ (from $7 \times 10^{6}$ to $6 \times 10^{5}$ ).

The numbers are indicative and only intend to demonstrate the methodology. However, the examples illustrate the potentially enormous impact of fatigue deterioration on the life expectancy of masonry bridges.

As discussed earlier, the SMART method proposes a methodology for estimating the life expectancy for masonry arch bridges. If the SN curve is known, for any stress level the associated life expectancy can be estimated. Also, the permissible limit state may be used as a safe limit below which no deterioration would occur for the expected lifetime of the structure. For traffic loading for example, if the life expectancy of a bridge is around 300 years, under non-realistic constant 24/7 loading at $2 \mathrm{~Hz}$, the maximum number of vehicles/ axles over the bridge would be up to ca. $2 \times 10^{10}$. The associated stress levels 
Table 1: $\quad$ Examples of approximate life expectancy based on the model by Casas (10\% minimum stress).

\begin{tabular}{|c|c|c|}
\hline \multicolumn{3}{|c|}{ Compression } \\
\hline Stress & Life expectancy \\
\hline$\%$ & Cycles & Ratio \\
\hline 45 & $8 \times 10^{9}$ & 35 \\
\hline 50 & $2 \times 10^{8}$ & 1 \\
\hline 55 & $1 \times 10^{7}$ & $1 / 20$ \\
\hline
\end{tabular}

\begin{tabular}{|c|c|c|}
\hline \multicolumn{3}{|c|}{ Shear } \\
\hline Stress & \multicolumn{2}{|c|}{ Life expectancy } \\
\hline$\%$ & Cycles & Ratio \\
\hline 45 & $1 \times 10^{8}$ & 18 \\
\hline 50 & $7 \times 10^{6}$ & 1 \\
\hline 55 & $6 \times 10^{5}$ & $1 / 12$ \\
\hline
\end{tabular}

using Casas' model level for compression and shear are for example $43 \%$ and $38 \%$ of the average static strength respectively. Therefore, if the fatigue stress level is below the respective $43 \%$ and $38 \%$, no failure would occur during the lifetime of the bridge and could be classified as a safe limit. Naturally the SN relationship would be individual for each failure mode and masonry type. As masonry varies widely from bridge to bridge as well as brick to brick, as a first step typical material types should be considered (e.g. weak, medium and strong) and tested. It is only with time that sufficient test data can be generated and reliable deterioration models can be developed to assist long-term life-cycle management of masonry arch bridges.

\section{Conclusions}

Life-cycle management of bridges considers the initial construction, maintenance/strengthening during service life and eventual replacement. Deterioration over time is likely to be caused by loading and environmental impacts, and it is only through realistic understanding of the rate of deterioration that bridge management can optimise long-term traffic needs, interventions, costs environmental impact, etc. While masonry arch bridges have proved to be longest-term solutions with the lowest maintenance costs and environmental impact compared to concrete and steel alternatives, they are currently completely disregarded as viable options for new construction. Bridges are currently designed for up to 120 years. Long-term bridge management prospective and tools are required before budgets and environmental impact can be meaningfully optimised.

The SMART assessment method has been proposed specifically for masonry arch bridges; however test data, scientific understanding and practical tools are now needed to apply the methodology in practice. Results of a series of longterm (fatigue) laboratory test data are described and the rate of deterioration was considered for masonry for stress against number of cycles (SN curves). Permissible limit state and residual life were demonstrated. Available data suggests that increasing the long-term stress level for masonry arch bridges can reduce the life-expectancy dramatically. 


\section{References}

[1] Sustainable Bridges Project (2004) Assessment for Future Traffic Demands and Longer Lives, D1.2 European Railway Bridge Demography. Available from: http://www.sustainablebridges.net [accessed 19 July 2013].

[2] ASCE (2003) Report card for America's infrastructure, 2003 progress report: an update to the 2001 Report Card, ASCE, Reston, Virginia.

[3] Hayward, A. (2011) Train loads on bridges 1825 to 2010. International Journal for the History of Engineering \& Technology. 81 (2), pp. 159-191.

[4] Transportation Research Board of the National Academy of Sciences (TRB) (2013) Design Guide for Bridges for Service Life. SHRP 2 Renewal Project R19A. Available from: http://onlinepubs.trb.org/onlinepubs/shrp2 /SHRP2prepub R19AGuide.pdf [accessed 19 July 2013].

[5] Highways Agency (2007) Inspection manual for highway structures. The Stationery Office.

[6] Highways Agency (2007) Guidance document for performance measurement of highway structures. Part B1: Condition Performance Indicator. Association of Directors of Environment, Economy Planning and Transport (ADEPT).

[7] CIRIA (2006) Masonry arch bridges: Condition appraisal and remedial treatment (CIRIA C656).

[8] Roads Liaison Group (2005) Assessment of Highways Structures, A code of practice.

[9] Department for Transport (2012) Structures Asset Management Planning Toolkit.

[10] British Standards Institution (2006) BS EN ISO, 14040 Series, Environmental Management - Life cycle assessment - Principles and framework. London: British Standards Institution.

[11] Steele, K., Cole, G., Parka, G., Clarke B. and Harding, J. (2003) Environmental impact of brick arch bridge management, Proceedings of the Institution of Civil Engineers, Structures \& Buildings. 156 (SB3), pp. 273281.

[12] Highways Agency (1997) Design Manual for Roads and Bridges: The Assessment of Highway Bridges and Structures - Part 4, BA 16/97.

[13] Harvey, W. (1988) Application of the mechanism analysis to masonry arches. The Structural Engineer. 66 (5), pp. 77-84.

[14] Gilbert, M. and Melbourne, C. (1994) Rigid-block analysis of masonry structures. Structural Engineering. 72 (21), pp. 356-361.

[15] Fanning, P., and Boothby, T. (2001) Three-dimensional modelling and fullscale testing of stone arch bridges. Computers and Structures. 79 (29-30), pp. 2645-2662.

[16] Brandish, A. and De Francesco, U. (2004) Assessment of multispeed masonry arch bridges. I: simplified approach. ASCE Journal of Bridge Engineering. 9 (6), pp. 582-590. 
[17] De Felicia, G. (2009) Assessment of the load-carrying capacity of multispan masonry arch bridges using fibre beam elements. Engineering Structures. 31 (8), pp. 1634-1647.

[18] Melbourne, C., Wang. J. and Smith, C. (2009) Review of Assessment Methods for Masonry Arch Highway Bridges. CSS Masonry Arch Research Project.

[19] Melbourne, C., Wang, J. and Timor, A. (2007) A New Masonry Arch Bridge Assessment Method (SMART). Proceedings of the Institution of Civil Engineering - Bridge Engineering. 160 (2), pp. 81-87.

[20] AlShebani, M. and Sinha, S. (1999) Stress-strain characteristics of brick masonry under uniaxial cyclic loading. ASCE Journal of Structural Engineering 3. 125 (6), pp. 600-604.

[21] De Felice, G. and De Santis, S. (2010) Experimental and numerical response of arch bridge historic masonry under eccentric loading. International Journal of Architectural Heritage. 4 (2), pp. 115-137.

[22] Roberts, T., Hughes, T., Dandamudi, V. and Bell, B. (2006) Quasi-static and high cycle fatigue strength of brick masonry. Construction and Building Materials. 20 (9), pp. 603-614.

[23] Clark, G. (1994) Bridge analysis testing and cost causation project: serviceability of brick masonry. British Rail Research Report, LR CES 151.

[24] Choo, B. and Hogg, V. (1995) Determination of the serviceability limit state for masonry arch bridges. In: Melbourne. C., ed. Arch Bridges. Salford, 1995. London: Thomas Telford. pp. 529-536.

[25] Melbourne. C., Tomor, A. and Wang, J. (2004) Cyclic load capacity and endurance limit of multi-ring masonry arches. In: Roca, P. and Oñate, E. ed. Proceedings of 4th Arch Bridges Conference. Barcelona: CIMNE, pp. 375-384.

[26] Highways Agency (2001) Design Manual for Roads and Bridges: The Assessment of Highway Bridges and Structures - Part 3, BD 21/01.

[27] Schueremans, L. (2001) Probabilistic evaluation of structural unreinforced masonry. PhD Thesis, Civil Engineering Department, KU Leuven.

[28] Casas, J. (2011) Reliability-based assessment of masonry arch bridges. Construction and Building Materials. 25 (4), pp. 1621-1631.

[29] Tomor, A., Verstrynge, E. (2013) A joint fatigue - creep deterioration model for masonry with acoustic emission based damage assessment. Construction and building Materials. 43, pp. 575-588.

[30] Lee, M., Barr, B.(2004) An overview of the fatigue behaviour of plain and fibre reinforced concrete. Cement \& Concrete Composites. 26 (4), pp. 299305. 